\title{
Lev Vigotski: mediação, aprendizagem e desenvolvimento: uma leitura filosófica e epistemológica
}

Flávia Letícia Soares e Silva ${ }^{1}$

Os estudos sobre a aprendizagem relacionada ao desenvolvimento e permeada pela mediação, como a de professores, é uma discussão que se destaca para o psicólogo, pesquisador do ensino e da escola, Vigotski. As funções da docência e sua contribuição para as transformações humanas chamam a atenção de quem pesquisa. Diante disto, Janette Friedrich nos disponibiliza a obra Lev Vigotski: mediação, aprendizagem e desenvolvimento: uma leitura filosófica e epistemológica, a qual atrai primeiro pelo seu formato:

A novidade dessa publicação encontra-se no modo como a autora lê e dialoga com a teoria de Vigotski, como compreende e discute suas ideias, como nos convida a uma leitura que nos leva a pensar no interior do pensamento do autor. Como ela mesma diz, não se trata de reproduzir as ideias de Vigotski ou de falar dele, mas de pensar com ele (FRIEDRICH, 2012, p.7).

A introdução trata da importância de se atrelar as ciências humanas à educação, além de encontrar algo novo no olhar histórico nas obras do autor russo soviético Lev Sémionovitch Vigotski (1896-1934). Friedrich apresenta sua biografia com destaque para as atividades pedagógicas, lecionando em escolas públicas, profissionais e no instituto de formação de professores. Neste último, funda um laboratório de psicologia para o desenvolvimento de trabalhos experimentais sobre o ensino. Produtor de grandes obras e inúmeros trabalhos, o pensador, professor, psicólogo, infelizmente, faleceu cedo, aos 37 anos, ainda em momento muito produtivo, deixando muitos estudos a serem continuados. A partir disto, começa o diálogo da autora com Vigotski.

A obra divide-se em cinco capítulos, dos quais, os dois primeiros abordam a psicologia como ciência. O terceiro apresenta os instrumentos psicológicos com suas conceituações, experimentos e aplicações. Os últimos capítulos (quatro e cinco) são considerados muito

\footnotetext{
${ }^{1}$ Universidade São Francisco (USF) e FAE Centro Universitário, Curitiba, flavia.leticia@fae.edu
} 
importantes por consagrar a concepção da aprendizagem e do desenvolvimento da criança, inclusive, destacando a escola como instituição sócio-histórica, que é campo fecundo para problematizações.

O primeiro capítulo aborda a intenção de Vigotski de unificar a psicologia, facilitando o seu uso por professores, psicólogos praticantes e formadores. A originalidade vigotskiana, então, é destacada no que se refere ao diagnóstico que faz da crise da análise da psicologia. Começa relacionando o problema com as três abstrações primárias: da consciência, do comportamento e do inconsciente e denuncia esses múltiplos objetos da psicologia, não propondo uma abstração comum, mas focando na filosofia do conhecimento que sustenta as três frentes.

Vigotski elabora sua própria concepção epistemológica para produção científica em psicologia, sendo o projeto de uma psicologia geral e a proposta de métodos indiretos em seus elementos essenciais. Tratando da psicologia geral, ainda neste capítulo, a base encontra-se no trabalho sobre o conteúdo real dos conceitos imbricados no conhecimento científico. A psicologia como ciência é, então, tida como possível. Portanto, enfatiza que é preciso ter a correspondência entre o fato e o pensamento conceitual, que é produto das práticas científicas, para chegar ao conhecimento verdadeiro.

Relacionar, justamente, o conhecimento e a realidade é o objetivo do segundo capítulo. Vigotski, então, define dois métodos: direto e indireto. O método direto envolve a psicologia do homem normal (observações internas: introspecção atestável), o behaviorismo (observações externas) e o conceito de inconsciente. O autor o critica radicalmente, pois sustenta que determinadas frentes da psicologia não podem ser englobadas por este, como por exemplo, a psicologia da criança, baseando-se na sua própria percepção e fala ainda imatura.

Em contrapartida, o indireto coloca de um lado as ciências da natureza e, de outro, as ciências históricas. Com isto, propõe o psiquismo como conceito psicológico de base, destacando as partes da realidade que são importantes, já que a consciência não se dá conta de tudo. Os métodos indiretos, portanto, estão na construção de hipóteses, na reconstrução e na interpretação de traços filtrados que podem ser importantes para explicar o realizado. Esta mediatização indireta pelos conceitos ou pelos instrumentos é que torna possível a produção científica em psicologia. 
O capítulo três apresenta a ideia dos instrumentos psicológicos, com a função de não somente conhecer, mas de gerar mediação. Auxiliam, como fenômenos psíquicos mediatizadores, funções psíquicas superiores, exemplificadas pela atenção voluntária ou memória lógica. Desta maneira, Vigotski aborda um experimento que associava um relógio com o braço esquerdo e um lápis com o direito, para a vinculação indireta ou mediatizada ser realizada por crianças. Chama, então, de memorização artificial que chega ao resultado idêntico, porém de uma melhor forma, ao da natural com o uso do instrumento. É chamado de um meio de autorregulação e de autocontrole. Neste processo, Vigotski opõe o natural ao artificial.

O terceiro capítulo chama a atenção para o que deveria ser de interesse do psicólogo: a maneira como o ser humano utiliza seus processos naturais próprios e os meios utilizados para atingir seus objetivos. Para o pensador, a lógica da mediação deve indagar a maneira, com quais meios, o homem emprega as propriedades de seu tecido cerebral e controla a produção de seus processos psíquicos, o que Vigotski atrela à essência do processo de desenvolvimento humano.

Já a segunda ideia vigotskiana trabalhada neste capítulo é a de que toda psicologia deveria ser concreta para analisar os instrumentos psicológicos, tanto como meios de transferência nas relações sociais no domínio do psíquico quanto no que se refere ao indivíduo. Ao abordar as transferências realizadas entre pessoas para o psicológico (interior do homem), Vigotski confirma estar nesta relação a história real da operada e do aparelho do indivíduo. 0 sujeito interioriza as relações interpessoais que acontecem nas instituições sociais.

A formação dos conceitos na criança é tema do quarto capítulo. As reflexões de Vigotski começam ao criticar dois métodos dominantes na área: método da definição e método da abstração. A falha do método da definição, que relaciona o conceito à significação da palavra, é apresentada como aquela que não permite à criança relacionar o que vive em sua realidade (contexto "natural"), experimentada e compreendida. Assim, o saber verbal, baseado em outros conceitos, prevalece. $O$ método da abstração é aquele que generaliza, como ao resumir objetos pelos seus traços comuns. É como se algas e tulipas fossem apenas plantas, sem características próprias que as coloquem em demais categorias. A crítica de Vigotski está no fato de o papel da palavra ser negligenciado no processo de formação de conceitos, já que, para ele, a orientação e o domínio dos processos psíquicos estão no emprego do signo, como instrumento psicológico. 
Na sequência do capítulo, são apresentados dois estudos experimentais. O primeiro deles, denominado de Dispositivo de Ach, com foco na utilização de conceitos para crianças resolverem situações de problema, é considerado frágil por Vigotski, pois falha no papel concedido à palavra. E por que a palavra é considerada um meio tão essencial na formação de conceitos para a equipe vigotskiana? A resposta é a de que a criança forma conceitos com a ajuda das palavras, que desempenham o papel de instrumentos psicológicos.

O segundo é o experimento de Sakharov/Vigotski, que usa palavras desprovidas de sentido para identificar conceitos experimentais. Apesar de as palavras dirigirem a formação de conceitos, Vigotski percebe a primeira diferença na concepção da linguagem, já que, na experiência, qualquer objeto pode tomar o lugar da palavra. Diferentemente do que acontece no mundo real, no qual o pensamento não é expresso na palavra, mas realizado nela, constituindo um processo único. Assume-se, deste modo, que a conceitualização acontece por meio da palavra.

A segunda diferença está relacionada à idade das crianças que implica em diferentes estados de formação de conceitos de acordo com a ontogênese infantil. Somente na adolescência é que se terá o estágio final da maturidade do pensamento conceitual. Sequencialmente, são abordados os estágios de formação de conceitos: sincréticos, complexos e o verdadeiro conceito. Na fase dos conceitos sincréticos, a criança usa a mesma palavra para fazer referência a diferentes objetos, como quando pequena chama todos os veículos (carro, bicicleta e carrinho de bebê) de auto. O estágio dos conceitos complexos compreende relações objetivas entre coisas e pessoas, para exemplificar, cita-se o caso da associação do sobrenome para membros da mesma família. $O$ verdadeiro conceito envolve ligações únicas e idênticas entre elas.

Uma importante observação é a de que, para Vigotski, a palavra é "onde" o pensamento nasce e permite pensar, não apenas representar, o mundo. Neste estágio, o homem é capaz de relações além do seu ser de fato do conceito, como quando a criança questiona: como um homem pode ser um animal, se o animal não tem razão/ não pensa? Conforme o autor, o objeto primário da psicologia do desenvolvimento deve ser as diferentes maneiras pelas quais os objetos são conceitualizados e pensados. 
O quinto e último capítulo aborda o aporte específico da escola, iniciando por distinguir os conceitos científicos dos cotidianos. Exemplifica com a linguagem oral que deve ser usada para mediar a aprendizagem escrita. Antes de entrar na escola, a criança tem o saber-fazer mesmo não tendo consciência que o possui, como o fato de não saber escrever, mas saber falar. Com total relação, abordam-se os conceitos de aprendizagem e desenvolvimento tão relacionados à pesquisa vigotskiana.

Diante de três teorias apresentadas, Vigotski se posiciona a favor daquela que afirma haver uma total interdependência nos processos de aprendizagem e desenvolvimento. Para ele, o conhecimento é construído pela criança, não sendo dado e nem adquirido. A partir disso, surge o conceito de Zona de Desenvolvimento Proximal. Diferentemente do desenvolvimento presente, movimenta o que a criança sabe fazer em direção ao que pode conseguir fazer. O foco dos ensinos escolares deveria ser o poder fazer. Neste caminho, Vigotski se opõe a duas teorias de sua época: uma que defende que o desenvolvimento não depende da educação escolar e outra oposta que assume que o desenvolvimento da criança depende exclusivamente do que é adquirido na escola.

A importância da escola no desenvolvimento humano é destaque no livro. O convívio social gerado pelo ambiente escolar e o incentivo às diversas formas do pensar promovidas pelas ações dos professores, ambos vistos como de grande importância por Vigotski em seus estudos, emergem no diálogo da autora.

A forte presença da palavra e sua contribuição ao desenvolvimento da criança também instiga a traçar um paralelo ao estimulado pelo Círculo de Bakhtin quando aborda a interação discursiva promovendo que:

A importância da orientação da palavra para o interlocutor é extremamente grande. [...] Enquanto palavra, ela é justamente o produto das inter-relações do falante com o ouvinte. [...]. Na palavra, eu dou forma a mim mesmo do ponto de vista do outro e, por fim, da perspectiva da minha coletividade. A palavra é uma ponte que liga o eu ao outro (VOLÓCHINOV, 2018, p.205).

É significativa a relevância desta obra para o estudo da educação que, mesmo focada primordialmente em crianças, pode ser estendida. Ao abordar temas como a psicologia atrelada ao ambiente educacional, traz à tona a possibilidade de aplicação em diversos ambientes, como 
o universitário, que envolve a relação social permeada pela aprendizagem e o desenvolvimento. Cabe deixar, inclusive, sugestões para pesquisas focadas no Ensino Superior, seguindo a linha desta temática.

Possibilidades para aplicar na formação docente também podem ser constatadas no livro. O papel do professor, como daquele que incita a transformação para o desenvolvimento do estudante, é apontado como foco para a geração do conhecimento científico verdadeiro. É, por meio do trabalho docente, incentivar a aprendizagem, aproximando da realidade do aluno além da escola e entendendo que são seres humanos distintos em sala de aula.

\section{Referências}

FRIEDRICH, J. Lev Vigotski: mediação, aprendizagem e desenvolvimento: uma leitura filosófica e epistemológica. Trad. Anna Rachel Machado e Eliane Gouvêa Lousada. Campinas: Mercado de Letras, 2012.

VOLÓCHINOV, V. Marxismo e a filosofia da linguagem: problemas fundamentais do método sociológico na ciência da linguagem. Trad. Sheila Grillo e Ekaterina Vólkova Américo. 2. ed. São Paulo: Editora 34, 2018.

Recebido em dezembro 2020.

Aprovado em junho 2021. 